\title{
DIÁLOGO VIVIDO ENTRE ENFERMEIRA E MÃES DE CRIANÇAS COM CÂNCER ${ }^{1}$
}

\author{
LIVED DIALOGUE BETWEEN NURSE AND MOTHERS OF CHILDREN WITH CANCER \\ EL DIÁLOGO VIVIÓ ENTRE LA ENFERMERA Y MADRES DE NIÑOS CON EL CÁNCER
}

\section{Nailze Figueiredo Souza de Oliveira ${ }^{2}$, Solange Fátima Geraldo da Costa ${ }^{3}$, Maria Miriam Lima da Nóbrega ${ }^{4}$}

RESUMO: O aumento progressivo do número de casos de crianças com câncer no Brasil tem despertado muitos profissionais da saúde para a realização de pesquisas que contribuam para uma assistência de qualidade para essa clientela e seus familiares. Este estudo consiste em uma pesquisa de campo de natureza qualitativa, direcionada ao cuidar em enfermagem, cujo objetivo foi compreender o diálogo vivido entre enfermeira e mães de crianças com câncer à luz da Teoria de Enfermagem Humanística de Paterson e Zderad. As participantes do estudo foram seis mães que acompanhavam suas crianças com câncer, na unidade de pediatria de um hospital. O diálogo vivido foi desenvolvido com base nas fases da Enfermagem Fenomenológica (Preparação da enfermeira para vir a conhecer; $A$ enfermeira conhece o outro intuitivamente). Nesta fase, os dados emergiram dos encontros entre enfermeira e mães a partir da técnica de entrevista e foram registrados no diário de campo. As demais fases serviram de base para a análise dos dados, que se constituiu nos momentos da relação Eu-Isso: A enfermeira conhece o outro cientificamente; $A$ enfermeira sintetiza de forma complementar as realidades conhecidas e Sucessão interna da enfermeira do múltiplo para a unidade paradoxal. Da análise dos dados emergiram as seguintes categorias: Mães diante da descoberta do diagnóstico; Mães diante do tratamento da criança; Mães diante da adaptação ao ambiente hospitalar; Mães carentes de informações; Mães com problemas no contexto familiar; Mães com saúde física e emocional afetada; Mães buscando formas de enfrentamento; Mães vivenciando momentos de alegria. O diálogo vivido intuitiva e cientificamente possibilitou às mães receberem cuidados que promovessem o seu bem-estar e estar-melhor na situação vivenciada com seus filhos. Também possibilitou a reflexão, conceitualização e descrição de um fenômeno que revelou o ser-com e o fazercom da enfermeira numa relação humanística com mães de crianças com câncer.

PALAVRAS-CHAVE: Cuidados de Enfermagem; Enfermagem Oncológica; Fenomenologia.

ABSTRACT: The progressive increase of cases of children with cancer in Brazil has stimulated many health professionals to develop researches which contribute to a better quality of health assistance to this clientele and their families. This study consists of a qualitative design of field research which aim to understand the lived dialogue between nurse and mothers of children with cancer grounded in Paterson and Zderad's Humanistic Nursing Theory. The study participants were six mothers who accompanied their children with cancer in the hospital pediatric unit. The lived dialogue was developed based on the phases of Phenomenological Nursing (Preparing the nurse knows; Nurse knowing of the other intuitively). In this phase, the data emerged from the meeting between nurse and mothers using the technique of interview and were recorded in the field diary. The other phases served as a basis to data analysis, which constituted in the moments of the relation I-This: Nurse knows the other scientifically; Nurse complementarily synthesizing known others and Sucession within the nurse from the multiple to the paradoxical one. From data analysis emerged the following categories: Mothers front of the diagnosis discovering; Mothers front of the child treatment; Mothers front of the adaptation to the hospital environment; Mothers information needing; Mothers with problems in the family context; Mothers with physical and emotional health affected; Mothers searching ways of coping; Mothers living happiness moments. The dialogue intuitive and scientifically lived made it possible for the mothers to receive care which would promote their well-being and more-well--being in that lived situation with their children. It was, then, made possible the reflection, conceptualization and description of a phenomenon which revealed the nurse being-with and doing-with in a humanistic relation with mothers of children with cancer.

KEY WORDS: Nursing Care; Oncologic Nursing; Phenomenology.

\footnotetext{
1 Dissertação de Mestrado apresentada ao Programa de Pósgraduação em Enfermagem CCS/UFPB.

${ }^{2}$ Mestre em Enfermagem Fundamental pelo Programa de PósGraduação em Enfermagem da Universidade Federal da Paraíba Docente da Escola Técnica de Saúde da UFPB. João Pessoa, PB. e-mail: nailzef@yahoo.com.br

3 Doutora em Enfermagem pela EERP-USP e Docente do Programa de Pós-graduação em Enfermagem da Universidade Federal da Paraíba. João Pessoa, PB. solangefgc@gmail.com (Orientadora)

4 Doutora em Enfermagem pela EERP-USP e Docente do Programa de Pós-graduação em Enfermagem da Universidade Federal da Paraíba. João Pessoa, PB. miriam@ccs.ufpb.br
} 
RESUMEN: El aumento progresivo de casos de niños con el cáncer en Brasil ha estimulado a muchos profesionales de salud para la realización de investigaciones que contribuyen para una ayuda de la calidad para esta clientela y sus familiares. Este estudio consiste de una abordaje cualitativo de investigación de campo, dirigido a entender el diálogo vivido entre la enfermera y las madres de niños con el cáncer fundamentado en la Teoría de Enfermería Humanística de Paterson y de Zderad. Los participantes del estudio fueron seis madres que acompañaron a sus niños con el cáncer en la unidad de la pediatría de un hospital. El diálogo vivido fue desarrollado en base de las fases de la Enfermería Fenomenológica (Preparación de la enfermera a venir saber, El saber intuitivo de la enfermera). En esta fase, los datos emergieron de la reunión entre la enfermera y las madres usando la técnica de entrevista y fueron registrados en el diario del campo. Las otras fases servieron como base para el análisis de los datos, que constituyó en los momentos de la relación Yo-Esta: La enfermera conoce el otro científicamente; La enfermera sintetiza de forma

\section{INTRODUÇÃO}

No Brasil, o câncer infantil atinge mais de cinco mil crianças e adolescentes, levando a mais de dois mil óbitos por ano nas idades de 0 a 19 anos, verificando-se um progressivo aumento de casos. Embora o Ministério da Saúde divulgue a cura em $70 \%$ dos casos, atribuídos aos avanços no diagnóstico e tratamento da doença, afirma também que isso só pode ser conseguido quando o diagnóstico é precoce e a criança recebe o devido tratamento em instituição especializada (INSTITUTO NACIONAL DO CÂNCER, 2003). Por outro lado, o difícil acesso à informação e atendimento nos serviços de saúde, retarda o diagnóstico e dificulta o tratamento e a cura.

Nas instituições de saúde, observa-se claramente que a mãe é o membro da família que acompanha a criança com maior freqüência, tanto ao tratamento ambulatorial como hospitalar. Dessa forma, se torna também um cliente que necessita dos cuidados de enfermagem. Segundo ORIÁ et al (2004), a qualidade dos serviços de saúde passa pela necessidade de se considerar a visão da família "de forma a estarmos sensíveis para oferecer um cuidado que atenda às expectativas do cliente e da família diminuindo a repercussão do estresse e ansiedade no processo de hospitalização."

Segundo as autoras BLACK \& MATASSARIN (1996), os impactos causados pelo câncer envolvem aspectos físicos, psicossociais e financeiros sobre a vida do cliente e seus familiares. Os aspectos físicos incluem muitas vezes modificações físicas ocasionadas pelos tratamentos básicos utilizados, complementaria las realidades sabidas; y la sucesión interna de la enfermera del múltiplo para la unidad paradójica. De la análisis de los datos emergió las siguientes: Madres delante al descubrimiento del diagnostico; Madres delante del tratamiento del niño; Madres delante de la adaptación al ambiente del hospital; Madres desprovistas de la información; Madres con problemas en el contexto familiar; Madres con salud física y emocional afectada; Madres que buscan formas de la confrontación; Madres que viven profundamente momentos de la alegría. El diálogo intuitivo y científicamente vivido permitió para que las madres reciban los cuidados que promovieron su bienestar y su mejor bien-estar en la situación vivida con sus niños. También posibilitó la reflexión, la concptualización y descripción de un fenómeno que reveló a la enfermera ser-con y hacer-con fundamentado en una relación humanística con las madres de niños con el cáncer.

PALABRAS CLAVE: Atención en Enfermería; Enfermería Oncológica; Fenomenología.

como o comprometimento da integridade cutânea, a queda do cabelo ou mutilações, causando mudanças na aparência. Os aspectos psicossociais relacionamse a sentimentos de ansiedade e depressão; estes são considerados os mais comuns, embora sejam evidentes as diferentes reações de clientes e familiares. O impacto financeiro diz respeito aos custos do diagnóstico e tratamento, existindo situações em que os planos de seguro públicos ou privados não assumem o custo total do tratamento. $\mathrm{O}$ impacto na família do doente é refletido na alteração do cotidiano, gerando estresse e assumindo características próprias da forma de enfrentamento individual de cada cliente e sua família.

A atuação da enfermeira junto ao cliente e familiares abrange cuidados nos diversos níveis de atendimento à saúde que incluem: atuação nos níveis de prevenção primária, secundária e terciária; planejamento e implementação de intervenções apropriadas ao cliente e família; atualização dos conhecimentos técnico-científicos, aplicando-os à clientela e atuação junto à equipe interdisciplinar. A complexidade do atendimento assemelha-se às outras especialidades no que se refere aos objetivos e responsabilidades. Entretanto, percebe-se um desafio específico no cuidar do cliente com câncer e sua família, uma vez que tal enfermidade carreia sentimentos de dor e morte fortemente acentuados em nossa sociedade (SMELTZER \& BARE, 2000).

$O$ interesse em relação ao cuidado de enfermagem para mães de crianças com câncer partiu de minhas experiências acadêmicas, assistenciais e de docência. Como docente ministro a disciplina Enfermagem em Oncologia, com aulas 
práticas desenvolvidas no Hospital Napoleão Laureano, referência no tratamento do câncer no Estado da Paraíba.

$\mathrm{Na}$ Unidade Pediátrica percebia diferentes atitudes de mães que acompanhavam seus filhos. Algumas aparentemente confiantes e tranqüilas, outras apreensivas, chorando ou impacientes com suas crianças nos momentos de punção venosa. Também observei que algumas mães expressavam dúvidas e desconhecimento em relação à doença e ao tratamento. Diante destas e de outras situações, surgia a pergunta que me inquietava: Como a equipe de enfermagem pode assistir mães de crianças com câncer em uma unidade de pediatria?

Ao ingressar no Curso de Pós-Graduação em Enfermagem em nível de mestrado, senti o desejo de desenvolver uma pesquisa direcionada ao cuidado de enfermagem a mães de crianças com câncer, utilizando uma teoria de enfermagem. Dedicando-me ao estudo de diversas teorias escolhi a que mais se adequou a minha visão de mundo e ao desenvolvimento da pesquisa: a Teoria de Enfermagem Humanística de Paterson e Zderad.

Diante das reflexões sobre minhas vivências como enfermeira, bem como sobre as complexidades inerentes ao câncer infantil e à atuação da enfermeira no atendimento à criança com câncer e sua família, este estudo teve por objetivo: compreender o diálogo vivido entre enfermeira e mães de crianças com câncer à luz da Teoria de Enfermagem Humanística de Paterson e Zderad.

\section{Considerações sobre a Teoria de Enfermagem Humanística}

A Teoria da Enfermagem Humanística surgiu na década de 1970 a partir das vivências das enfermeiras Josephine Paterson e Loretta Zderad no campo da docência e da assistência em Enfermagem. O conteúdo da teoria revela a influência do existencialismo, do humanismo e da fenomenologia.

As teóricas PATERSON \& ZDERAD (1988) propõem que a Enfermagem seja desenvolvida como uma experiência existencial, onde a enfermeira, após vivenciá-la, reflete sobre ela, e descreve fenomenologicamente os chamados e respostas que surgiram na relação, bem como o conhecimento adquirido através da experiência. A experiência existencial significa o conhecimento humano do eu e do outro; é reconhecer o outro em sua singularidade, como alguém que luta e se esforça para sobreviver, chegar a ser, confirmar sua existência e entendê-la.

As dimensões principais da Enfermagem Humanística derivam da situação humana onde a Enfermagem é vivida. Segundo PATERSON \& ZDERAD (1988, p.18), os elementos do sistema são: "seres humanos (enfermeira e cliente) em um encontro (ser e vir a ser) com um fim determinado (nutrir o bem-estar e o estar-melhor) numa transação intersubjetiva (ser com e fazer com) acontecendo no tempo e espaço (delimitado e vivido pelo cliente e enfermeira) em um mundo de homens e coisas."

Para descrever o fenômeno de Enfermagem, as teóricas utilizam os seguintes conceitos: bem-estar e estar-melhor, potencial humano, transação intersubjetiva, ser e fazer. A Enfermagem também é considerada um diálogo vivido entre enfermeira e cliente que envolve os seguintes conceitos: Encontro, Relação, Presença, Chamado e Resposta.

A relação entre enfermeira e cliente tem por objetivo o bem-estar e o estar-melhor do cliente, que participa como sujeito ativo do processo e que vê na enfermeira possibilidades de ajuda e de suporte. Essa relação é entendida segundo as três dimensões descritas por BUBER (1979): a relação Eu-Tu (sujeito-sujeito), a relação Eu-isso (sujeito-objeto) e a relação Nós.

Segundo KLEIMAN (2001), o propósito da Enfermagem é nutrir o bem-estar e o estar-melhor das pessoas. Esse nutrir é a habilidade de participar em situações de enfermagem e de esforçar-se com os outros nas suas experiências de saúde e de sofrimento para a atualização do seu potencial, ou seja, a enfermeira ajuda o cliente a tornar-se o melhor possível em sua situação particular.

Para PATERSON \& ZDERAD (1979), a prática da Enfermagem e sua fundamentação teórica estão inter-relacionadas. A enfermeira é aquela que desenvolve sua prática como um ser humano que sente, valoriza, reflete e conceitua. Do cotidiano da Enfermagem surge o conjunto organizado do conhecimento clínico.

\section{Enfermagem Fenomenológica}

Para PATERSON \& ZDERAD (1979, p.127). "a teoria da enfermagem humanística se forma na interação dialógica das experiências articuladas e compartilhadas por enfermeiras investigadoras que abstraem e conceituam". Com esse pensamento as teóricas criaram a metodologia ENFERMAGEM FENOMENOLÓGICA que pode ser aplicada no cuidado e na pesquisa em Enfermagem. A metodologia é desenvolvida em cinco fases:

\section{Preparação da enfermeira para vir a conhecer}

Nesta fase, a enfermeira busca conhecer a si própria e, neste processo, corre o risco de confrontarse com sua possível incapacidade de perceber a si mesma e de tornar seus pensamentos e atitudes mais humanas. Trava-se uma luta interna ao ver-se como pessoa rígida e preocupada com o status quo, confrontando-se com seus valores, devendo estar consciente de seu próprio ponto de vista e democraticamente aberta para os pontos de vista dos outros. Existem várias formas de se chegar ao conhecimento interior e uma delas consiste na leitura reflexiva de obras que falem sobre a natureza do homem e suas diferentes formas de perceber e relacionar-se com o mundo. A partir dessas reflexões, 
são feitas comparações com a prática da Enfermagem (PATERSON \& ZDERAD, 1979).

\section{A enfermeira conhece intuitivamente o outro}

O importante é o conhecimento que se tem do outro, o modo como vive e vê seu mundo. Isto se dá quando a enfermeira procura introduzir-se no tempo, ritmo e mobilidade do outro, levando a um conhecimento absoluto, intuitivo, inexpressável único do outro. Para conhecer alguém intuitivamente e vislumbrar seu potencial para vir a ser, é preciso "uma mente cognoscente, um eu capaz de distanciar-se do outro, de ver o outro, que se faz presente ao outro e reconhece a presença do outro."A enfermeira, responde à singularidade do cliente, não se impõe, mantém sua capacidade de surpresa, questionamento e presença autêntica. (PATERSON \& ZDERAD, 1979, p.121).

\section{A enfermeira conhece cientificamente o outro}

A enfermeira, após vivenciar o outro intuitivamente, conceitua a experiência e a expressa segundo o seu potencial humano. É o momento de refletir, analisar, classificar, comparar, contrastar, relacionar, interpretar, denominar e categorizar. As teóricas afirmam que nesse processo reflexivo, a enfermeira "analisa, considera as relações entre os componentes, sintetiza temas ou padrões, e então conceitualiza ou interpreta simbolicamente a visão seqüencial desta realidade vivida no passado." (PATERSON \& ZDERAD, 1988, p.73).

\section{A enfermeira sintetiza de forma complementar as realidades conhecidas}

Este é o momento de comparar e sintetizar as múltiplas realidades conhecidas, para então chegar a uma visão ampliada. A enfermeira, como conhecedora, estabelece relações entre essas realidades e então as interpreta, seleciona e classifica. Neste processo, as diferenças descobertas nas realidades semelhantes "não rivalizam, uma não nega a outra [...] diferenças só podem tornar visíveis as realidades maiores de cada uma". (PATERSON \& ZDERAD, 1979, p.123).

\section{Sucessão interna da enfermeira do múltiplo para a unidade paradoxal}

Através de reflexões e considerações sobre as relações entre as múltiplas visões, a enfermeira faz uma revisão compreensiva e expande sua própria visão. Segundo as teóricas PATERSON \& ZDERAD (1979, p.125), a enfermeira vai além das multiplicidades e contradições e "chega a uma concepção importante para a maioria ou para todos."

O método Enfermagem Fenomenológica não segue o Processo de Enfermagem convencional. Ele vai mais além ao propor às enfermeiras que desenvolvendo uma prática humanizada, a conceitualize e compartilhe. Dessa forma, a metodologia permite um avanço no processo de construção de um conhecimento originado do mundo vivido da Enfermagem.

\section{O CAMINHO METODOLÓGICO}

O desenvolvimento deste estudo foi norteado por uma pesquisa de campo de natureza qualitativa embasada na Teoria de Enfermagem Humanística de PATERSON \& ZDERAD (1988). O cenário da pesquisa foi a Unidade de Pediatria do Hospital Napoleão Laureano, referência no tratamento de doenças oncológicas, na cidade de João Pessoa Paraíba. As participantes desta investigação foram seis mães que acompanhavam seus filhos na Unidade Pediátrica no período de outubro a dezembro de 2002.

O processo de investigação foi norteado pelo Código de Ética dos Profissionais de Enfermagem Resolução n.240 do Conselho Federal de Enfermagem (COFEN, 2000) e pelas Diretrizes e Normas Regulamentadoras para Pesquisa Envolvendo Seres Humanos - Resolução n.196 do Conselho Nacional de Saúde (BRASIL, 2002). Para preservar o anonimato das mães, solicitei que elas escolhessem o nome de uma flor que as identificaria no estudo. Desse modo, foram identificadas pelos nomes das flores: Azálea, Cravo, Girassol, Rosa, Rosa Branca e Rosa Vermelha. A pesquisa só foi iniciada após aprovação do projeto de dissertação pelo Comitê de Ética em Pesquisa do Centro de Ciências da Saúde da Universidade Federal da Paraíba.

Os dados da pesquisa emergiram da relação Eu-Tu através da técnica de entrevista aberta e informal e registro em diário de campo. Aconteceram em média dez encontros com as mães, que eram intercalados por períodos de alta hospitalar que ocorriam de acordo com o esquema de tratamento e evolução clínica de cada criança.

A análise dos dados teve como fio condutor as três últimas fases da Enfermagem Fenomenológica: A enfermeira conhece o outro cientificamente; A enfermeira sintetiza de forma complementar as realidades conhecidas e Sucessão interna da enfermeira do múltiplo para a unidade paradoxal.

\section{DO AUTOCONHECIMENTO AO DIÁLOGO VIVIDO}

A metodologia Enfermagem Fenomenológica utilizada para o desenvolvimento deste estudo, foi descrita em três momentos nos quais estão inseridas as cinco fases da metodologia:

\section{Preparando-me para conhecer as mães}

Esse momento consistiu em um processo de autoconhecimento como requisito básico para desenvolver o diálogo vivido. Intensifiquei minhas reflexões sobre o meu modo de ser e agir, não apenas como enfermeira, mas também como ser que se relaciona com o outro. Também me dediquei à 
leitura de livros, teses e artigos; assisti a filmes e participei de congressos cujas temáticas foram pertinentes ao estudo. Essa fase contribuiu para o meu crescimento interior, ou seja, acrescentaram meu potencial humano no que concerne ao meu modo de ser no mundo e no processo de cuidar em Enfermagem.

\section{Conhecendo as mães intuitivamente - a relação eu-tu}

Nos encontros, a relação eu-tu me permitiu conhecer as realidades de cada mãe. Procurei manter uma relação horizontal pautada no respeito mútuo na solidariedade, me colocando no lugar das mães, imaginando como elas gostariam de ser atendidas, observando e utilizando formas de comunicação verbal e não-verbal.

Numa relação dialógica, ouvi-as narrar espontaneamente suas histórias relacionadas ao aparecimento da doença na criança, como também seus temores e dúvidas sobre a evolução e tratamento de seus filhos. Ao surgirem os chamados, surgiam as respostas que consistiram no meu cuidar das mães, através da atenção, da escuta e do toque, tentando transmitir segurança e apoio, expressando a minha solicitude. Além disso, forneci informações sobre a doença e o tratamento de seus filhos, e proporcionei momentos de descontração e relaxamento através da realização de uma dinâmica e de música ambiente.

\section{Conhecendo as mães cientificamente - a relação eu-isso}

Após vivenciar a relação intuitiva, seguiram-se as etapas de análise e descrição conforme a metodologia da Enfermagem Fenomenológica. As categorias emergiram a partir do modo como as mães se revelaram ao meu olhar, as quais apresentamos e dicutimos a seguir.

\section{Mães diante da descoberta do diagnóstico}

As mães falavam sobre a descoberta da doença desde os sinais e sintomas que as fizeram levar o filho ao médico até a constatação do diagnóstico definitivo. Além de expressarem as dificuldades, a preocupação, o sofrimento e o temor da morte do filho, as mães associavam o aparecimento do câncer com alguma doença préexistente como verminoses ou obstrução nasal, como revelam os relatos a seguir:

"Ele estava com a barriga grande e comia muito, pensei que era verme. Levei para o HU e encontraram um tumor no intestino." (CRAVO)

"Levei ele ao médico por causa de uma obstrução nasal, fui encaminhada para cá, depois dos exames, soube o que era. Pensei que ele ia morrer".(AZALÉA)
Diante do impacto do diagnóstico do câncer em seu filho, as mães tentam encontrar fatos que expliquem essa realidade. Nesse momento, são muitas as providências a tomar e dificuldades a enfrentar como marcações de consultas, exames, cirurgias, internamentos. Situações como essas necessitam de uma atenção especial no sentido de minimizar a ansiedade, a angústia, a tristeza e até mesmo a exaustão.

A enfermeira proporciona conforto às mães de crianças com câncer através do processo clínico da relação Eu-Tu e Eu-Isso, não só no momento da descoberta do diagnóstico, mas em toda e qualquer situação na qual sua presença é necessária ou é solicitada pelas mães através do chamado.Segundo PATERSON \& ZDERAD (1979, p.177), o conforto é o para que da Enfermagem e é evidenciado quando "uma pessoa é livre para ser e vir a ser, controlar e planejar o seu próprio destino, segundo seu potencial em uma situação particular."

\section{Mães diante do tratamento da criança}

As mães expressavam os momentos difíceis pelos quais passavam ao ver o sofrimento da criança, diante dos procedimentos invasivos. Também falavam sobre seu modo de cuidar, como podemos perceber nos relatos a seguir.

"Quando ele vai tomar a medicação na coluna, é sempre assim, ele chora e se debate muito, só fica calmo depois que é sedado." (ROSA)

"Ele está com estas placas brancas na língua, não estou limpando porque ele morde minha mão, só coloco o remédio amarelo." (GIRASSOL)

O tratamento da criança com câncer, geralmente envolve procedimentos invasivos e efeitos colaterais. As mães tentam entender e controlar a situação, baseadas em orientações da equipe de saúde ou em seus próprios modos de ver o problema e tomar decisões. Segundo PATERSON \& ZDERAD (1979, p.20), "[...] só cada homem pode descrever ou escolher o desenvolvimento do projeto representado por ele mesmo em sua situação."

A enfermeira vai ao encontro das mães nesses momentos, orientando quanto aos possíveis efeitos colaterais dos quimioterápicos e as formas de reconhecimento, prevenção e manejo de algumas complicações como infecções e hemorragias. Além disso, é importante enfatizar os benefícios das drogas, incentivando a continuidade do tratamento.

\section{Mães diante da adaptação ao ambiente hospitalar}

Algumas mães revelaram as dificuldades que elas e seus filhos enfrentavam no ambiente hospitalar 
como o sono prejudicado e a dificuldade em relacionar-se com as pessoas da instituição, como mostram os seguintes trechos:

"Eu não consegui dormir direito aqui. Ele chorou para não dormir no berço, ficou comigo no sofá, reclamei, mas não adiantou. Em casa ele dorme comigo na cama." (ROSA BRANCA)

"No início não me dava bem com ninguém no hospital, me sentia triste." (ROSA VERMELHA)

Os relatos revelam o modo de ser e agir das mães em relação ao mundo de homens e coisas que as cercavam no ambiente hospitalar. Segundo PATERSON \& ZDERAD (1979, p.63), ao ingressar em uma instituição de saúde, o cliente percebe-se "como um ser em um mundo estranho de objetos novos". Em lugar do seu ambiente familiar, passa a ver-se "rodeado por equipos, máquinas, instrumentos, soluções químicas etc. Eles podem sentir como algo que causa confusão, dá medo, causa dor, dá segurança, relaxa ou é vivificante."

Por outro lado, as mães referiram o apoio dos profissionais de saúde no ambiente hospitalar, como revelam os seguintes trechos:

"Estou sendo bem atendida e apoiada aqui no hospital, não tenho queixa de ninguém. As voluntárias são nossos anjos da guarda." (ROSA BRANCA)

"A equipe daqui é muito boa, ganhei pais e mães, não tenho o que falar do hospital. Quando tenho dúvidas você vem e responde." (ROSA VERMELHA)

Esses relatos revelam o reconhecimento das mães para com a equipe de saúde, voluntárias e pesquisadora, deixando claro o quanto é necessária a participação efetiva de todos a favor destes seres especiais que carecem de apoio para encorajá-las em suas trajetórias. Segundo SANTOS (2002, p.59) "o ambiente que agride é o mesmo que protege, que ampara, que sustenta, que acolhe, que permite que se diga, que se chore".

\section{Mães carentes de informações}

Na relação dialógica com as mães ouvi-as falar do desejo de saber mais sobre a nutrição da criança e sobre as dificuldades que enfrentavam para entender a doença e o tratamento dos filhos como mostram os seguintes relatos:

"Me empresta esse livro (sobre nutrição do cliente com câncer) para eu ler no final da semana, segunda-feira eu devolvo". (AZALÉA)
"Ele está de alta, não sei direito o dia do retorno. Recebi alguns papéis, mas não sei para que servem, vou buscar para te mostrar. Não sabia que eram para fazer exames, não sei ler". (ROSA BRANCA)

A incompreensão expressada por Rosa Branca torna evidente a existência de falhas na comunicação entre a equipe de saúde e as mães. Segundo PATERSON \& ZDERAD (1979, p.65) no diálogo genuíno, a enfermeira humanística entra "em harmonia com o ritmo do diálogo e, ao perceber a oportunidade de seu desenvolvimento, adequa o ritmo do seu chamado e resposta à capacidade do cliente para chamar e responder naquele momento." Essa sincronização quando evidenciada no estar com e no fazer com da enfermeira com as mães de crianças com câncer, acrescentará o potencial humano dessas mães o que se traduzirá no seu melhor entendimento sobre a doença e o tratamento de seus filhos.

\section{Mães com problemas no contexto familiar}

Algumas mães enfrentavam problemas no relacionamento familiar e dificuldades financeiras, como mostram as falas a seguir:

"Me sinto um pouco distante do meu marido e do outro filho, não estou dando a eles a mesma atenção de antes e algumas pessoas da família se afastaram. Tive alguns problemas com meu pai." (ROSA VERMELHA)

"Trabalhava de cabeleireira, fechei o salão há três meses para cuidar do meu filho. $O$ pai dele está desempregado e não me dá nada para ajudar, só vou começar a receber o benefício do INSS da criança no próximo mês". (CRAVO)

Os problemas no contexto familiar pareciam ter surgido ou se intensificado a partir do aparecimento do câncer em um membro da família. As formas de reagir a esses problemas se manifestavam de acordo com os recursos disponíveis e com o modo de ser de cada mãe. Segundo PATERSON \& ZDERAD (1979, p.78), o modo de ser adotado por cada indivíduo em seu mundo "depende de seu grau de liberdade, da forma que sua família lhe faz perceber o mundo, de que aspecto deste the é mostrado e de como é percebido por ele."

Ao entrar na relação intersubjetiva com mães de crianças com câncer, A enfermeira também participa de acordo com o modo de ser que adotou para viver no mundo. Entretanto, esse modo de ser não é estático nem para as mães nem para a enfermeira. Ao exercerem sua influência na relação também são influenciadas e têm diante de si a oportunidade de vir a ser. 


\section{Mães com saúde física e emocional afetada}

Em alguns momentos, as mães falavam sobre seus problemas de saúde física e emocional que já existiam ou que se manifestavam devido aos diversos fatores relacionados à doença do filho, como revelam os trechos a seguir:

\section{"Estou com muita dor de cabeça. Estou com enxaqueca." (ROSA BRANCA) \\ "Estou sentindo algo estranho, me acho calada; estou cansada de não fazer nada". (CRAVO)}

As falas revelam que, em muitas ocasiões, as mães encontravam-se física e emocionalmente afetadas, devido a sucessivas noites com repouso parcial, às implicações da doença e do tratamento, ao sofrimento do filho e a impossibilidade de atender a necessidade de outros membros da família.

Para PATERSON \& ZDERAD (1988, p.12)., o interesse da enfermeira não deve centrar-se "unicamente no bem-estar de uma pessoa senão no seu estar-melhor, ajudando-a a tornar-se o mais humanamente possível em uma situação particular de sua vida." Neste contexto, a enfermeira humanística dirige o seu cuidar às mães, vendo-as na sua totalidade, buscando maneiras de valorizar algum potencial humano.

\section{Mães buscando formas de enfrentamento}

As mães procuravam diversas formas de enfrentamento, tentando minimizar o sofrimento e reorganizar suas vidas. Mesmo ante os acontecimentos dolorosos que as cercavam, mostravam sua disposição em lutar, sua fé e esperança em Deus e no tratamento, como expressam os relatos a seguir:

"Não podemos perder a fé em Deus e a esperança. Se Ele quiser levar quem sou eu para impedir, mas não perco a fé e estou lutando para cuidar dele" (GIRASSOL)

"Deu maligno, mas confio no tratamento. Não me importo com o tempo que vamos ficar aqui, o importante é que ele fique bom. Acredito que vai ficar só no olho." (ROSA)

As mães lutavam por uma condição de vida melhor para o seu filho com câncer, para outros membros da família e para si mesmas. Precisavam partir em busca do seu bem-estar e estar-melhor. A luta dessas mães travava-se em um mundo real de homens e coisas, no tempo e no espaço vividos.

Segundo PATERSON \& ZDERAD (1979, p.97)., a enfermeira, mesmo se colocando como presença autêntica para apoiar o cliente na luta pela sua liberdade, precisa compreender que os outros têm que decidir responsavelmente [...] estão só para decidir." As mães precisavam tomar decisões, aproveitar as oportunidades e utilizar o seu potencial humano para vir a ser.

\section{Mães vivenciando momentos de alegria}

Havia ocasiões em que as mães vivenciavam momentos de alegria que se devia a fatos como a melhora do quadro clínico dos filhos, a aproximação do término do tratamento, os resultados favoráveis dos exames, e as atividades de descontração realizadas pela pesquisadora, como revelam as seguintes falas:

"Esta é a última quimioterapia. Não deu mais
nada nos exames!" (AZALEA)
"Pense numa brincadeira boa!" [após a
realização da dinâmica]. (GIRASSOL)

Em alguns desses relatos, embora não houvesse expressões verbais que identificassem os momentos de alegria e satisfação, eles eram facilmente percebidos em suas formas de comunicação não-verbal. Segundo ASTI VERA (1989, p.80), "a autenticidade do encontro, se manifesta no olhar, no gesto, na mímica, no sorriso e até no silêncio."

É importante destacar as descobertas e mudanças positivas na vida de algumas mães após o surgimento do câncer em seus filhos, como expressam as falas a seguir:

"Aprendi muito, mudei a forma de pensar. Também procuro aceitar as palavras amigas e ser mais humilde. Não me importo se vou passar o natal sem dinheiro, o que importa é a saúde do meu filho". (ROSA VERMELHA) "Só descobri a fé que tenho em Deus quando meu filho adoeceu." (CRAVO)

Ao expressar os seus modos de ver a vida, agora transformados pela experiência vivida com a doença do filho, as mães revelam o crescimento do seu potencial humano, o vir a ser que se originou não somente da dor, mas do seu próprio esforço e da presença daqueles que se mostraram solícitos no cuidar.

Em geral, na literatura sobre câncer infantil sempre é mostrado o lado funesto da experiência. Entretanto, alguns estudiosos da psicologia que atuam junto a clientes com câncer e seus familiares, falam dos ganhos secundários relacionados às experiências com o câncer, seja para o cliente ou para a família. Segundo SIMONTON (1990, p.168), esses ganhos podem ser tangíveis como a melhora dos hábitos alimentares, da qualidade do sono e de exercícios físicos. Os ganhos intangíveis estão relacionados "à filosofia de vida, aos sentimentos e aos relacionamentos." Nem todos conseguem 
vislumbrar esses ganhos, entretanto, é uma realidade comprovada pelas pessoas que a vivenciam.

\section{REFLETINDO O DIÁLOGO VIVIDO COM AS MÃES}

Este momento corresponde a última fase da Enfermagem Fenomenológica: Sucessão interna da enfermeira do múltiplo para a unidade paradoxal.

Diante das vivências com mães de crianças com câncer, refleti sobre o conhecimento intuitivo adquirido inicialmente e sobre o modo como as contemplo agora depois de vários diálogos vividos, comparações, análises e reflexões. Como não poderia deixar de ser, considerei atentamente o ser e o fazer da Enfermagem em uma unidade de oncologia pediátrica.

A maioria das mães passava por uma seqüência de momentos difíceis e dolorosos como a descoberta do diagnóstico, a internação, a cirurgia, a quimioterapia ou a radioterapia. Em meio a essa trajetória, surgiram as dificuldades para se adaptar ao ambiente hospitalar, as dúvidas e incertezas quanto à doença, o tratamento e a cura do filho. Também havia a necessidade de aprender a realizar cuidados com a criança aos quais não estavam acostumadas, além da saudade e preocupações com outros filhos.

As mães expressavam também, que em alguns momentos sentiam-se estressadas, cansadas, tentando administrar os conflitos gerados pelas mudanças ocorridas no seu cotidiano. Diante dessas vivências, buscavam mecanismos de enfrentamento que consistiam em sua fé e esperança em Deus e no tratamento, no compartilhar de suas vivências com outras pessoas e na busca por ajuda. Era evidente a disposição em lutar e a solidariedade entre as mães.

Coloquei-me como presença, disponível para ouvir e confortar, incentivando a fé e a esperança. PATERSON \& ZDERAD (1979) afirmam que assim como a enfermeira vê possibilidades no cliente, o cliente também as vê na enfermeira, como por exemplo, possibilidades de ajuda, conforto e apoio.

Ao compartilhar momentos de dor e tristeza com as mães, senti a grande diferença entre ser uma enfermeira que atua "de longe", mediada apenas pelo fazer, e ser uma cuidadora que entra numa relação de ser-com as mães de crianças com câncer. Ao sercom demonstramos nosso amor ao próximo e nos expomos a sentimentos de dor, bem expressados por SIMONTON (1990, p.16): "mas, quando amamos, devemos arriscar. $\mathrm{O}$ amor nos torna receptivos a sermos afetados, desapontados, feridos [...]".

Os momentos vividos na unidade de pediatria revelaram a importância da presença da enfermeira, promovendo o bem-estar e o estar-melhor das mães através da escuta, das orientações, de um olhar, de um toque.

São várias as atividades da enfermeira em uma unidade de oncologia pediátrica. Destaco a necessidade de sua presença no momento da comunicação do diagnóstico à criança e à família, podendo ser um momento de apoio e de vislumbres para futuras intervenções. A interação ao longo de todo processo possibilitará à enfermeira uma visão ampla de todas as necessidades que as mães poderão vir a apresentar. É imprescindível a atuação de uma enfermeira ambulatorial trabalhando em conjunto com a enfermeira da unidade de internação, uma vez que, geralmente, o tratamento alterna-se entre ambulatorial e hospitalar.

O diálogo vivido possibilitou às mães receberem cuidados que promovessem o seu bemestar e estar-melhor na situação vivida. Permitiu a reflexão, conceitualização e descrição de um fenômeno que revelou o ser-com e o fazer-com da enfermeira numa relação humanística com mães de crianças com câncer. Originou uma nova concepção, a atualização do meu potencial humano e um estarmelhor para as próximas vivências como enfermeira a cuidar de mães de crianças com câncer. Segundo PATERSON \& ZDERAD (1979, p.32), “[...] o caráter transacional intersubjetivo da Enfermagem não pode passar despercebido quando se vive o fenômeno, seja como enfermeira ou como cliente."

\section{REFLEXÕES FINAIS}

Desenvolver este estudo foi uma experiência singular e transformadora, onde teoria e prática se fizeram presentes, permeadas pela visão existencialfenomenológica-humanista, objetivando um cuidado humanístico e ao mesmo tempo contribuindo para a construção do corpo de conhecimento da Enfermagem, para uma prática fundamentada, sobre a qual se reflete, se abstrai e se conceitua, levando a um processo de retroalimentação, enfim, fazendo crescer a Enfermagem, principalmente favorecendo o bem-estar e o estar-melhor do cliente, e ainda levando a enfermeira a crescer como ser.

Com o avanço da ciência e da tecnologia e a modernização de procedimentos, "vinculados à necessidade de se estabelecer controle, o enfermeiro passou a assumir cada vez mais encargos administrativos, afastando-se gradualmente do cuidado ao paciente, surgindo com isso a necessidade de resgatar os valores humanísticos da assistência de enfermagem." (BEDIN et al., 2005, p.118),

Aplicar a Enfermagem Fenomenológica no cuidar e na pesquisa me fez refletir sobre a importância da busca do autoconhecimento aliado ao processo de cuidar, das relações Eu-Tu e Eu-Isso acontecendo ao-mesmo-tempo na situação de enfermagem e da conceitualização e descrição fenomenológica da prática de enfermagem. Utilizandome das palavras de PATERSON \& ZDERAD (1979), posso afirmar que me tornei mais humana, mais inquisitiva e mais clínica, em uma palavra, mais.

Os pressupostos da Teoria de Enfermagem Humanística incentivam a enfermeira a refletir sobre si mesma, redirecionar o seu cuidar, vir-a-ser, tornar- 
se melhor na sua relação com o cliente e sua família. Toda sua riqueza de conteúdo deve ser ainda mais explorada pela Enfermagem, podendo ser inserida em qualquer situação da assistência, pesquisa ou do ensino. Para isso, é necessário divulgá-la ainda mais, mostrando sua aplicabilidade através de estudos que aliem a teoria e a prática. Segundo PATERSON \& ZDERAD (1979, p.35), a Enfermagem humanística é "uma meta pela qual se deve lutar [...] um valor importante que enriquece a prática da Enfermagem."

Foram muitas as ocasiões em que no diálogo vivido, houveram chamados e respostas. As respostas de Enfermagem manifestaram-se de várias formas: ouvindo, dando conforto, carinho e atenção, esclarecendo dúvidas, compartilhando o conhecimento, estando presente e sendo presença, chamando e respondendo, participando do cotidiano, relacionando-se com outros familiares, proporcionando momentos de descontração e relaxamento, proporcionando conforto espiritual, ajudando no cuidar dos seus filhos e relacionando-se com eles: dando atenção e carinho, realizando procedimentos de enfermagem quando necessário, realizando atividades de lazer, estimulando o desenvolvimento e atendendo aos seus chamados.

Nos últimos encontros com as mães pude observar que conseguiam conviver melhor com todas as complexidades envolvidas no cuidado a sua criança. Conviver com as mães e com as crianças me proporcionou momentos de crescimento como ser humano e profissional.

Este estudo possibilitou novas perspectivas para o meu agir no cuidar em enfermagem, no ensino, pesquisa e extensão que terão como referencial norteador os pressupostos da Teoria de Enfermagem Humanística, uma vez que acredito que é humanizando o nosso modo de agir que conseguiremos repassar o valor da assistência humanizada de enfermagem.

\section{REFERÊNCIAS BIBLIOGRÁFICAS}

ASTI VERA, A. A. Metodologia da Pesquisa Científica. 8 ed. São Paulo: Globo, 1989.

BEDIN, E; RIBEIRO, L.B.M.; BARRETO, R.A.S.S. Humanização da assistência de enfermagem em centro cirúrgico. Revista Eletrônica de Enfermagem. 2005. [online] Disponível em: http://www.fen.ufg.br/revista/revista7 1/revisao 04.h tm [Acesso em 25 jul 2006).

BLACK, J. M.; MATASSARIN-JACOBS, E. Luckmann \& Sorensen - enfermagem médico-cirúrgica: uma abordagem psicofisiológica. 4. ed. Rio de Janeiro: Guanabara Koogan, 1996.

BRASIL. Ministério da Saúde. Conselho Nacional de Saúde. Manual Operacional para Comitês de Ética em Pesquisa. Brasília, 2002.

BUBER, M. Eu e tu. Tradução de Newton Aquiles Von Zuben. 2. ed. São Paulo: Cortez \& Moraes, 1979.
CONSELHO FEDERAL DE ENFERMAGEM. Código de ética dos profissionais de enfermagem. Rio de Janeiro, 2000.

INSTITUTO NACIONAL DO CÂNCER. Particularidades do câncer infantil. Rio de Janeiro, 2003. Disponível em: <http://www.inca.gov.br>. [Acesso em 5 fev. 2003].

KLEIMAN, S.J. Josephine Paterson and Loretta Zderad: humanistic nursing theory with clinical applications. In: PARKER, M. E. Nursing Theories and Nursing Practice. Philadelphia: F. A. Davis Company, 2001.

ORIÁ, M. O. B.; MORAES, L. M. P.; VICTOR, J. F. - A comunicação como instrumento do enfermeiro para o cuidado emocional do cliente hospitalizado. Revista Eletrônica de Enfermagem. 2004. [online] Disponível em:

http://www.fen.ufg.br/revista/revista6 2/comunica.html (Acesso em 25 jul 2006)

PATERSON J. G.; ZDERAD, L. T. Enfermería humanística. México: Limusa, 1979. Humanistic Nursing. New York: NLN, 1988.

SANTOS, M. E. M. A criança e o câncer: desafios de uma prática em psico-oncologia. Recife: A.G.Botelho, 2002.

SIMONTON, S. M. A família e a cura: o método Simonton para famílias que enfrentam uma doença. São Paulo: Summus, 1990.

SMELTZER S. C.; BARE, B. G. Brunner \& Suddarth Tratado de enfermagem médico-cirúrgica. 8. ed. Rio de Janeiro: Guanabara Koogan, 2002.

Artigo original recebido em 02/04/2006

Aprovado para publicação em 30/04/2006 